ARTIGOS

\title{
REFLEXÕES SOBRE OS ASPECTOS SIMBÓLICOS DAS MARCAS SOB A ÓTICA DA TEORIA INSTITUCIONAL
}

\section{RESUMO}

Este ensaio teórico buscou incitar uma discussão sobre a importância da marca como ativo intangível no processo de legitimação e diferencial competitivo organizacional, respaldando-se nas orientações e nos pressupostos da teoria institucional. A perspectiva institucional abandona a concepção de um ambiente organizacional formado, exclusivamente, por recursos humanos, materiais e econômicos para destacar a presença de elementos culturais como valores, símbolos, mitos, sistema de crenças e programas profissionais. Neste sentido, a marca configura-se como um importante ativo estratégico, meio sustentável de diferenciação e legitimação para a empresa, capaz de carregar valores simbólicos e agregar um maior valor aos bens disponibilizados no mercado.

Palavras-chave: Marca. Teoria Institucional. Isomorfismo. Ativos Intangíveis.

Natalia Contesini dos Santos netycontesini@hotmail.com Doutoranda em Administração pelo IAG PUC-Rio. Mestre em Administração pela Universidade Federal Rural do Rio de Janeiro (UFRRJ). Atuou como pesquisadora bolsista da Fundação de Amparo à Pesquisa do Estado do Rio de Janeiro (FAPERJ).

\section{Tamirez Dornelles Pires Grammatikopoulos tami_dornelles@hotmail.com Mestranda em Administração pela UFRRJ. Discente no pro- grama de Mestrado Acadêmico em Administração pela UFRRJ. \\ Camila Arantes de Paula Medina camila.turismo15@gmail.com Mestranda em Administração do Programa de Pós-Gradua- ção em Administração - PPGA/ UFRRJ.}

\section{INTRODUÇÃO}

Atualmente, o mercado globalizado impõe um mesmo conjunto de exigências e condições ambientais às empresas, em um cenário incerto, restrito e altamente controlador. Estas pressões externas fazem que as organizações assumam formas e práticas previsíveis, controladas e/ou conservadoras, buscando regras padronizadas e modelos de sucesso em uma tentativa de minimizar incertezas e variabilidades nos processos e de atender exigências do mercado. Ao longo do tempo, essas organizações tendem a se assemelhar umas às outras, incorrendo em um processo de homogeneização, tendo em vista o condicionamento das mesmas particularidades dos ambientes em que se inserem e, consequentemente, pelas demais instituições inseridas nesse ambiente (GREENWOOD et al., 2011).

Diante deste processo de homogeneização organizacional, o gerenciamento de recursos torna-se ainda mais estratégico para organizações, uma vez que representam potenciais ferramentas para a criação de legitimidade e diferenciais competitivos. Contudo, nem todos os recursos podem garantir uma vantagem competitiva sustentável, visto que alguns podem ser imitados ou facilmente 
substituídos ou comercializáveis. Uma vez que os aspectos técnicos de uma organização podem ser igualados ou, rapidamente, superados pelos concorrentes, deve ser dado um foco organizacional maior para o gerenciamento de aspectos simbólicos, como itens difíceis de serem imitados.

Nesse sentido, a marca configura-se como um importante ativo estratégico, capaz de trabalhar com valores simbólicos e agregar um maior valor aos produtos e serviços disponibilizados no mercado. Mais do que um meio de identificação de produtos e serviços, a marca caracteriza-se como um importante ativo intangível para a empresa, sendo, consequentemente, uma forma exclusiva de diferenciação da empresa em meio a sua concorrência. Além disso, a gestão correta da marca pode ser fonte de vantagens competitivas, como também, facilitar o processo de legitimação organizacional.

Desse modo, este ensaio teórico busca discutir sobre a importância da marca como ativo intangível no processo de legitimação e diferencial competitivo organizacional. Tal discussão será conduzida sob as orientações e os pressupostos da teoria institucional, como uma perspectiva que defende o ambiente organizacional composto por um sistema de elementos técnicos, valores e crenças socioculturais que deve ser atendido pelas organizações que buscam legitimidade e aceitação (GREENWOOD et al., 2011).

A atenção da abordagem institucional à análise de elementos de redes relacionais, aspectos simbólicos e de sistemas culturais, que formam e sustentam a estrutura e ação das organizações, possibilita a reconceitualização do ambiente organizacional, permitindo novas discussões e preocupações para os estudos organizacionais. Como abandona a concepção de um ambiente formado exclusivamente por recursos humanos, materiais e econômicos para destacar a presença de elementos culturais - valores, símbolos, mitos, sistema de crenças e programas profissionais - (CARVALHO; VIEIRA; LOPES, 1999), a teoria institucional permite que as empresas vislumbrem um modo de se diferenciarem no mercado isomórfico ao darem ênfase a seus valores simbólicos.

Para atingir tal objetivo, este estudo está estruturado em quatro seções, além desta introdução. Na segunda seção, são realizadas considerações sobre a abordagem institucional nos estudos organizacionais e sobre as marcas. Em seguida, são apresentadas as reflexões sobre a influência da marca no processo de legitimação e diferencial competitivo organizacional, balizadas sob a ótica da teoria institucional. Por fim, a quinta seção compreende as considerações finais deste exercício reflexivo.

\section{TEORIA INSTITUCIONAL}

A partir da década de 1950, os estudos organizacionais começam a direcionar-se a favor de perspectivas de administração baseadas em sistemas abertos, que conceituavam as organizações como estruturas sujeitas às pressões do ambiente no qual se inserem (ASSIS et al., 2010). Contudo, ao longo da evolução desses estudos, o que se entendia por ambiente sofreu profundas e importantes mudanças. Enquanto as teorias contingenciais e ecológicas focavam nos elementos técnicos e financeiros do ambiente de funcionamento organizacional, a teoria institucional propunha que as características organizacionais fossem condicionadas pelos fatores sociais e culturais desse ambiente (DACIN; GOODSTEIN; SCOTT, 2002).

A proposta dos institucionalistas é a necessidade de se considerar o ambiente organizacional como aquele formado não somente por variáveis técnicas, mas também por variáveis intangíveis, parte de um sistema de crenças e de normas socioculturais (DUARTE; TAVARES, 2012). O foco reside, de um lado, na relação de influência mútua entre organizações e ambientes organizacionais, e do outro, nas estruturas normativas e culturais mais amplas. Assim, as organizações devem ser vistas como algo além de sistemas de produção; sendo também importantes sistemas culturais e sociais (SCOTT, 2004).

A teoria institucional admite que o am- 
biente organizacional seja composto por elementos técnicos e simbólicos e exige que as organizações considerem, além dos recursos materiais, tecnológicos e capitais, necessários para seu processo produtivo, os valores gerados a partir de elementos culturais - como marcas, valores, símbolos, mitos e sistema de crenças - e a adequação e a aceitação das normas e exigências sociais (ASSIS et al., 2010). Assim, o ambiente institucional é constituído por um sistema de elementos técnicos, valores e crenças socioculturais, responsável por ditar parâmetros de concepção da realidade para as organizações (GUARIDO FILHO; MACHADO-DA-SILVA; GONÇALVES, 2009).

A organização, como instituição, abrange regras informais que se seguem a partir de processos de socialização e expectativas socialmente desejáveis, conferindo valores, deveres e responsabilidades que definem o que é certo e o que é errado (CARVALHO et al., 2016). Para os adeptos da abordagem institucional, uma vez que este ambiente reflete o que a sociedade acredita ser a maneira correta de a empresa se organizar e se comportar, as organizações que atendem e, principalmente, institucionalizam esses ditames técnicos e socioculturais incrementam sua legitimidade e seus propósitos de sobrevivência. Desse modo, a sobrevivência das organizações não é garantida unicamente pelo mercado, pelos ditames tecnológicos ou pela máquina pública, mas também pelo conjunto de orientações técnicas e simbólicas do ambiente que foi institucionalizado em suas estruturas organizacionais (GREENWOOD et al., 2011; THORNTON; OCASIO; LOUNSBURY, 2012).

Contudo, a partir do momento em que passam a enfrentar o mesmo conjunto de pressões ambientais, as empresas tendem a adotar estruturas, comportamentos e atividades similares e a assumir formas e práticas organizacionais previsíveis, controladas e/ou conservadoras. O conjunto de padrões de comportamento, de normas e de valores, de crenças e de pressupostos, na qualidade de elementos socialmente estáveis, impõem limitações às alternativas de ações ou estabelecem roteiros adequados es- pecíficos de interação social (PRATES, 2000). A tendência é que, em longo prazo, essas empresas assumam determinadas estruturas e processos como regras e construam, em torno de si, ambientes que negligenciem a necessidade de mudança ou até a sua possibilidade. Assim, o processo de diversificação dentro do campo é minimizado, ocasionando o fenômeno de isomorfismo institucional, por meio de mecanismos coercitivos, miméticos e normativos (DiMAGGIO; POWELL, 2005; GREENWOOD et al., 2011).

No primeiro caso, segundo DiMaggio e Powell (2005), uma organização mais forte exerce pressões formais e informais sobre outra que lhe seja dependente. Assim, o isomorfismo coercitivo decorre do problema da legitimidade, provenientes das pressões do ambiente sob a organização e da influência política. Esse mecanismo está relacionado aos rituais de conformidade, às leis e aos regulamentos que, de alguma maneira, permitem a padronização dos comportamentos ou descrevem comportamentos esperados. Embora as pressões coercitivas sejam frequentemente associadas a requisitos governamentais e regulatórios, essa força também pode ser decretada em organizações de qualquer outra natureza que tenha a autoridade de aplicar sanções a uma organização, se não agir de acordo com as suas solicitações (WASHINGTON; PATTERSON, 2011).

$\mathrm{O}$ ato de tomar outras organizações como modelos, seja pela liderança, legitimação, seja pelo sucesso no mercado, e copiar suas práticas levaria ao isomorfismo mimético. Esse mecanismo está ligado às organizações que se espelham ou imitam outras empresas com o propósito de minimizar temores tecnológicos, atenuar conflitividades entre seus objetivos, driblar a falta de recursos ou atender exigências institucionais (CARVALHO; VIEIRA, 2003).

Por fim, o isomorfismo normativo está associado a formas comuns de interpretação e de ação em face dos problemas organizacionais (GREENWOOD et al., 2011). Esse mecanismo, por ser fruto da profissionalização e do incentivo à produção de conhecimento padro- 
nizado, contribui para a uniformização de pensamentos, práticas e comportamentos, sejam estes profissionais ou organizacionais, assim como para o apreço pelo mesmo universo de procedimentos, estruturas e políticas.

\section{MARCAS}

Desde a Antiguidade, já existiam diversas maneiras de promoção de mercadorias e serviços. Segundo Pinho (1996, p. 11), "sinetes, selos, siglas e símbolos eram [...] utilizadas como um sinal distintivo e de identificação para assinalar animais, armas e utensílios." Essas 'marcas' comunicavam a procedência do produto, atestando seu prestígio e sua excelência, sendo maneiras para os indivíduos analfabetos identificarem os comerciantes e suas mercadorias.

Para Aaker (2015), marca é um nome e/ ou símbolo distintivo destinado a identificar e distinguir os bens ou serviços de um vendedor de outros idênticos, semelhantes ou afins, de origem diversa. Contudo, Kapferer (2012) explica que essa função única de identificação e diferenciação foi ampliada quando a teoria dominante de marketing sofreu influência de aspectos da psicologia cognitiva. Nesse momento, enquanto buscava conhecer melhor as formas de influenciar o comportamento dos consumidores, o marketing descobriu o potencial das marcas como forma única de apelo ao consumo, indo muito além das funções clássicas de distinção da concorrência e identificação do produtor. Dessa forma, ampliou-se o conceito de marca com o intuito de incluir sua capacidade de carregar características intangíveis, como valores, sentimentos, ideias ou afetos (KAPFERER, 2012), que sobrepujam, até mesmo, à prestação funcional ou à qualidade do produto ou serviço (AAKER, 2015).

A capacidade simbólica das marcas é, similarmente, reconhecida por Keller (2016), quando conceitua marca como o conjunto de elementos funcionais, simbólicos e experienciais que representam uma empresa. Por trás de uma marca, escondem-se os elementos físicos do produto, a satisfação pessoal no uso do bem ou serviço, suas vantagens intrínsecas e extrínsecas, além da imagem organizacional, do nome, da visão, da cultura, dos posicionamentos, da identidade visual, entre outros. Logo, uma marca é responsável por fazer a ligação física e simbólica entre a empresa e o consumidor, carregando, assim, todas as lembranças, experiências, posicionamentos e percepções vividas pelos consumidores. Desse modo, as marcas aparecem não como elementos agregados aos produtos e serviços de uma organização, mas como entidades cognitivas complexas, criadas pelos consumidores a partir da totalidade de suas experiências de uso dos bens em si, de suas percepções culturais e sociais, ou de questões de personalidade e identidade que lhes são proporcionadas (KELLER, 2016).

Aaker (2015) aponta que, ao redor de uma marca, existe um conjunto de ativos capazes de acrescentar (ou retirar) valor a uma empresa ou a seus clientes. $\mathrm{O}$ autor defende que a notoriedade, a fidelidade, a qualidade percebida e as associações feitas à marca ajudam a alterar percepções e experiências do consumidor a respeito de um determinado produto ou serviço, estando esses fatores fortemente relacionados à criação de marcas organizacionais fortes e à determinação de vantagens organizacionais. Entende-se como notoriedade a força da presença da marca na mente do consumidor, enquanto a fidelidade mede a ligação do consumidor com a marca, refletindo a probabilidade de esta ser trocada por outra diante de variáveis de mercado. A qualidade percebida pode ser definida como a percepção que o consumidor tem da qualidade global ou da superioridade de um produto ou serviço em relação à concorrência. Por fim, as associações que os consumidores fazem a partir do uso da marca estão intimamente relacionadas com a imagem e a significação que a organização pretende que a marca tenha na mente dos consumidores.

Geralmente, existe a correlação direta e intuitiva entre marca e identidade visual. A identidade visual é o símbolo gráfico de uma empresa, sendo, muitas vezes, o primeiro contato que os indivíduos têm com ela (CIMATTI, 
2007). Essa pode ser desde um simples ícone, um lay-out específico, uma tipografia ou as cores características da marca. Assim, quando a empresa é legitimada no mercado em que atua, a marca será facilmente reconhecida pelos consumidores graças à sólida institucionalização de sua identidade visual.

Uma vertente da literatura de marketing propõe uma visão institucional da dinâmica do mercado. Scaraboto e Fisher (2013), por exemplo, estudam como consumidoras e blogueiras norte-americanas plus-size $e^{l}$ utilizam o discurso institucionalizado pelo mercado da moda dominante para reivindicar o fornecimento de mais opções de roupas da moda em tamanho plus-size. Similarmente, Dolbec e Fischer (2015) investigam o papel que os consumidores podem desempenhar na legitimação de uma dada prática de consumo. Nessa vertente, os consumidores são vistos como agentes interpretativos, não passivos, que buscam criar, manter ou interromper categorias cognitivas ou práticas e representações institucionalizadas pelo mercado, por meio, principalmente, da publicidade massiva. Contudo, Stuart (2018) defende que a abordagem da lógica institucional ainda não foi exaustivamente utilizada como lente para a investigação da marca.

\section{REFLEXÕES SOBRE MARCAS E TEORIA INSTITUCIONAL}

A teoria institucional defende o ambiente organizacional composto por um sistema de elementos técnicos, valores e crenças socioculturais que deve ser atendido pelas organizações que buscam legitimidade e aceitação. Assim, o ambiente institucional projeta, nas organizações, a necessidade de se definirem estratégias de ação, exercendo pressões que as influenciam a fim de garantir a sobrevivência e a legitimidade.

Suddaby (2010) observa que, uma vez legitimadas, as organizações adquirem vida própria, independente de quaisquer de seus membros, tendo o seu valor não mais atrelado unicamente à sua eficiência e à demanda de seus produtos ou serviços, mas a si mesmo.
Esse fenômeno pode ser ilustrado pelo trecho abaixo, que demonstra a legitimidade da Porsche, uma das principais marcas de automóveis esportivos do mundo. O sólido e representativo simbolismo da marca, representando valores de sofisticação, estilo e engenharia de precisão, permite e sustenta, por si só, a extensão dos negócios da empresa para segmentos que não o automobilístico. Logo, a notoriedade da marca, sua qualidade percebida e as associações a elas feitas são capazes de comunicar a credibilidade que a empresa possui junto ao mercado.

[...] as características de sofisticação, estilo e engenharia de precisão dos carros Porsche podem ser plausivelmente transportadas para relógios Porsche, óculos de sol Porsche, e até mesmo para roupas, máquinas fotográficas e malas Porsche. Qualquer extensão do nome Porsche que mantenha os atributos essenciais de estilo, sofisticação e alta qualidade são apropriados e merecem credibilidade, além de tudo podem servir para desenvolver a marca e não prejudicá-la (MURPHY, 1990, p.112 apud PINHO, 1996, p. 25).

Ilustrando a abordagem institucional, é possível afirmar que os aspectos técnicos da Porsche podem ser facilmente copiados por seus concorrentes do segmento automobilístico, incorrendo no fenômeno de isomorfismo mimético. Contudo, o poder de sua marca permite à organização manter uma vantagem competitiva no segmento no qual atua ou pretende atuar.

Similarmente, tem-se o processo de extensão da marca Dona Benta, líder no mercado brasileiro em vendas nas categorias de farinha de trigo e misturas para bolos. Criada em 1979, a marca Dona Benta sempre esteve fortemente atrelada à cultura popular brasileira, graças à associação que fazia a personagem de Monteiro Lobato com o mesmo nome. Além disso, o investimento em programas de culinária e cursos de gastronomia ajudou a fortalecer a identificação da marca com as donas de casa brasileiras. 
Por exemplo, o caso de extensão da marca Dona Benta, que produzia primeiramente apenas farinha de trigo, uma categoria de produtos considerada commodity, por possuir baixo valor agregado e muitos concorrentes. A extensão de marca a levou a lançar produtos como massas prontas para bolo, massas para bolinhos de chuva e fermento em pó, categorias que permitem margens de lucros mais atraentes, todos estes produtos carregando a marca Dona Benta, já consolidada e conhecida como farinha de trigo de alta qualidade (RIBEIRO, 2006, p. 107).

Cumpre ressaltar que o baixo valor agregado do produto, o número significativo de concorrentes e, consequentemente, de possíveis bens substitutos no mercado tornam difícil o processo de fidelização do consumidor junto à marca Dona Benta. É possível concluir, ainda, que o processo de isomorfismo institucional não traria resultados significativos para essa organização e seus concorrentes, uma vez que a produção dos bens de um fabricante para o outro não possui diferenças expressivas. Todavia, a capacidade de carregar características intangíveis, como valores associados à tradicionalidade e à alta qualidade, permite que a marca Dona Benta incremente os negócios da empresa, constituindo-se como ponto de diferenciação e vantagem competitiva em um segmento de commodities.

A teoria institucional defende que as incertezas do mercado se tornam incentivo à imitação, observando a tendência da adoção de ferramentas ou modelos válidos e aceitos externamente. Tal constatação pode ser ilustrada pela passagem, abaixo, que descreve a preferência dos gerentes de Centros de Processamento de Dados (CPD's) por produtos IBM, unicamente pelos aspectos simbológicos desta empresa.

Há algumas décadas, por exemplo, os gerentes dos CPDs adquiriam preferencialmente os sistemas da IBM, pagando mais caro a fim de benefi- ciar-se da forte imagem de marca, sinônimo de qualidade e de tecnologia avançada. [...] Independentemente do fato de esses sistemas serem realmente superiores aos demais do ponto de vista técnico, a institucionalização da marca da IBM, como sinônimo de qualidade superior e a atitude conservadora dos gerentes dos CPDs para defender suas posições foi um fator importante nas vendas e na expansão da empresa (MOTTA; VASCONCELOS, 2002, p. 404).

Holt (2002) defende que, ao adquirir uma marca, o consumidor não compra apenas o bem em si, mas todo um conjunto de valores e atributos tangíveis e intangíveis que contribuem para diferenciar o produto ou o serviço daqueles que lhe são similares, ou seja, a notoriedade da marca IBM, sua qualidade percebida e as associações a elementos como qualidade e tecnologia avançada são capazes de comunicar, ainda que incorretamente, uma superioridade técnica em relação aos concorrentes. Nesse sentido, as construções simbólicas associadas a essa marca sobressaem, até mesmo, a prestação funcional de seus processadores.

Para Chandra, Griffith e Ryans Junior (2002), o advento da internet contribuiu para revolucionar os processos de comunicação, diminuindo as barreiras globais, de tal forma que aumenta a visão global ou multinacional das organizações, estabelecendo-as como padrões a serem seguidos. Existe, então, a tendência de que as empresas maiores sirvam de modelo para as menores, aumentando as chances do isomorfismo mimético, corroborando Callado, Callado e Almeida (2011, p. 208) ao afirmarem que esse tipo de isomorfismo "se refere à adoção de padrões em resposta à incerteza." Paralelamente, em face de um cenário incerto, restrito e altamente controlador, as organizações irrompem-se ao mimetismo, ao buscarem reproduzir elementos de organizações já consolidadas no ambiente. Logo, a condição ambiental mercadológica das organizações é classificada como mimética, pelo fato de as organizações decidi- 
rem, sob essas condições de incerteza, que o caminho mais seguro é, justamente, copiar o que foi feito por organizações mais bem-sucedidas.

Essa prática aparece em campanhas de publicidade e outras ações de marketing, de muitos produtos, com o objetivo de facilitar o processo de aceitação e legitimação da empresa. Portanto, fazendo o uso, principalmente, da identidade visual de empresas líderes de mercado. Percebe-se, então, que o intuito não é a apropriação dos elementos técnicos dessas empresas, mas os aspectos simbólicos que, subjetivamente, estão atrelados à legitimação e à solidez que essas empresas possuem nos segmentos em que atuam.

Fabricantes de amidos de milho, de diferentes marcas, buscam manter suas identidades visuais semelhantes à 'caixinha amarela' da marca líder Maizena, da Unilever (Fig.1), assim como o concorrente Melken faz com a 'caixinha vermelha' de chocolate em pó da líder de mercado alimentício Nestlé (Fig.2). A fabricante Ice Cola usa as cores e lay-out da marca líder mundial Coca-Cola (Fig.3), da mesma forma que a marca Ritter faz com a embalagem e as cores utilizadas pela Queensberry, líder no mercado de geleias premium (Fig.4). Outro caso semelhante se dá com a identidade visual do leite condensado Moça, da Nestlé (Fig.5), o sabonete Protex, da Colgate-Palmolive (Fig.6), o cereal de flocos de milho Sucrilhos, da Kellogg's (Fig.7), e os produtos de limpeza multiuso Veja, da Reckitt Benckiser (Fig.8).

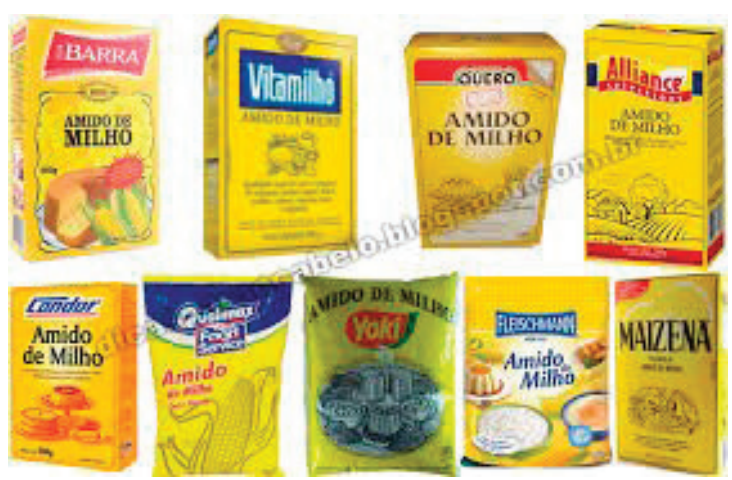

Figura 1- Amido de milho Maizena, da Unilever (à esquerda, abaixo)

Fonte: (DICAS PARA O CABELO, 2012).

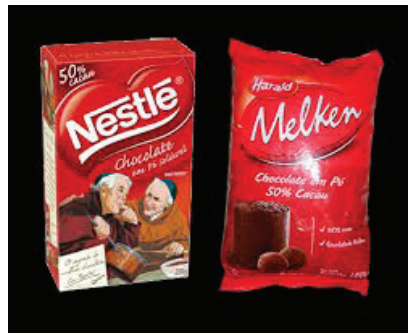

Figura 2 - Chocolate em pó solúvel, da Nestlé (à esquerda)

Fonte: (BARREIRINHAS, 2015).

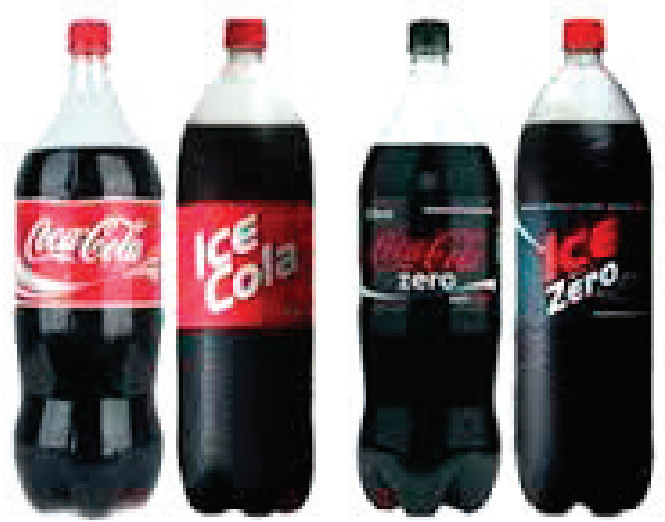

Figura 3 - Refrigerante de cola, da Coca-Cola (à esquerda e ao centro)

Fonte: (VALOR ECONÔMICO, 2012).

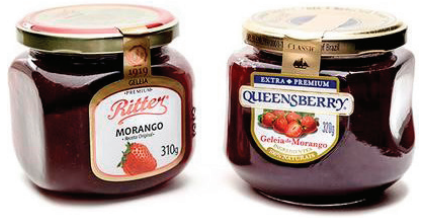

Figura 4 - Geleia Queensberry (à direita) Fonte: (PORTUGAL, 2014).

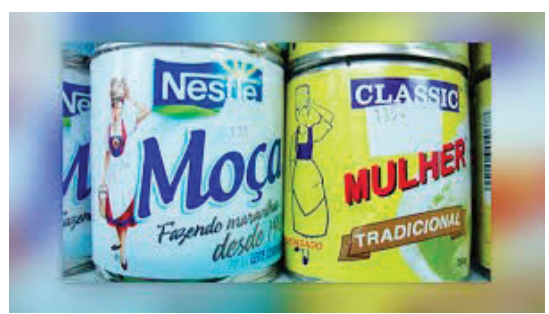

Figura 5 - Leite condensado Moça, da Nestlé (à esquerda)

Fonte: (ZORZETTO, 2012). 


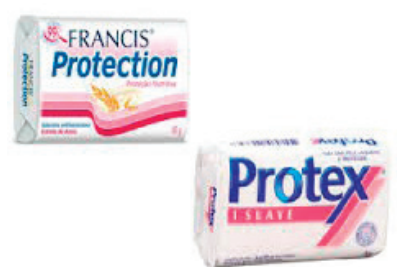

Figura 6 - Sabonete Protex, da Colgate-Palmolive (à direita)

Fonte: (SABONETE..., 2012).

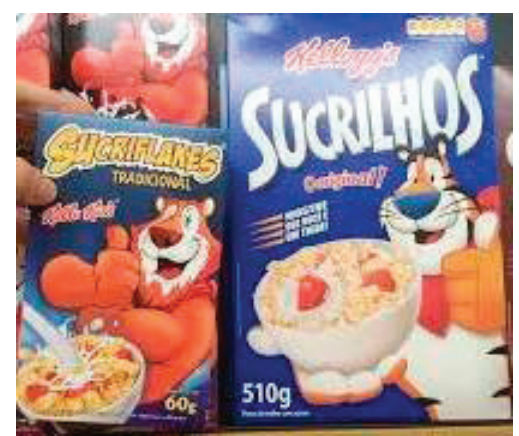

Figura 7 - Cereal de flocos de milho Sucrilhos, da Kellogg's (à direita)

Fonte: (LOWIS DESING, 2012).

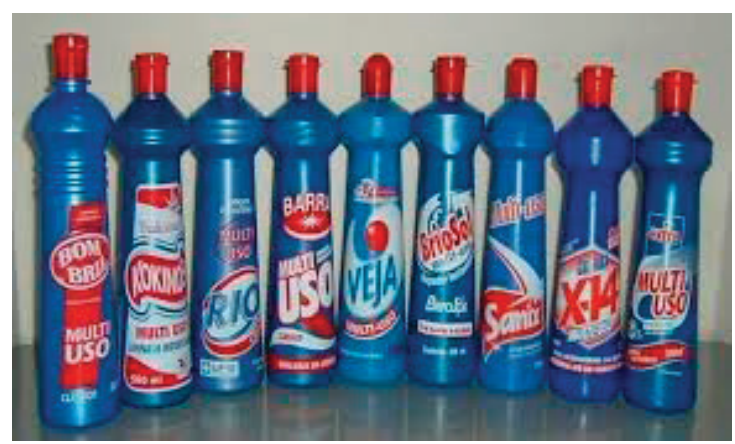

Figura 8 - Produto de limpeza multiuso Veja, da Reckitt Benckiser (ao centro)

Fonte: (BIG MUNDO INFANTIL, 2013).

Para sobreviver, as organizações devem convencer seu público de que são entidades legitimadas e merecedoras de suporte (MEYER; ROWAN, 1991). Essa preocupação em demonstrar a legitimidade das organizações incentiva a condução de muitas pesquisas com o intuito de classificar as empresas, baseando-se na sua reputação e no valor de suas marcas. A veracidade é tanta que, em 2016, as marcas esportivas Nike e Adidas valiam, respectivamente, US\$ 27 bilhões e US\$ 7 bilhões (FOR-
BES BRASIL, 2016). Não obstante, essas são marcas cujas identidades visuais são muito plagiadas em itens esportivos (Figura 9-14). Segundo Reich (2002), as organizações que possuem as marcas mais valiosas usufruem de um maior grau de confiança, o que representa liderança, respeito e legitimidade em seus campos de negócio.

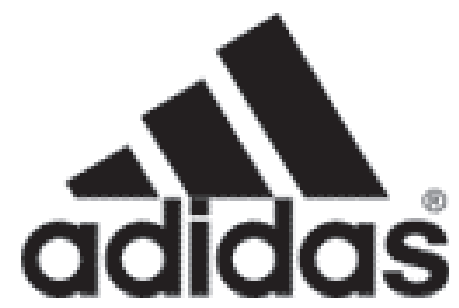

Figura 9 - Identidade visual Adidas. Fonte: (ADIDAS, 2017).

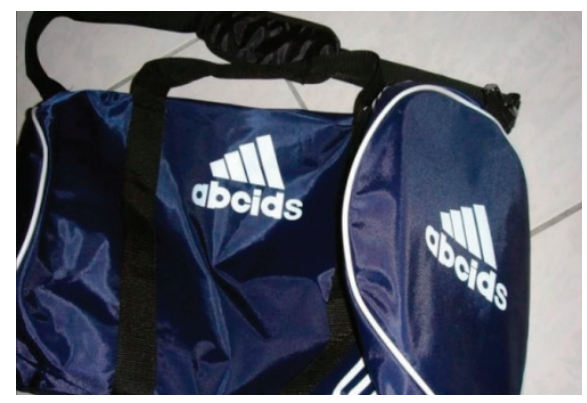

Figura 10 - Uso plagiado da identidade visual Adidas em bolsa esportiva.

Fonte: (MELLO, 2011).

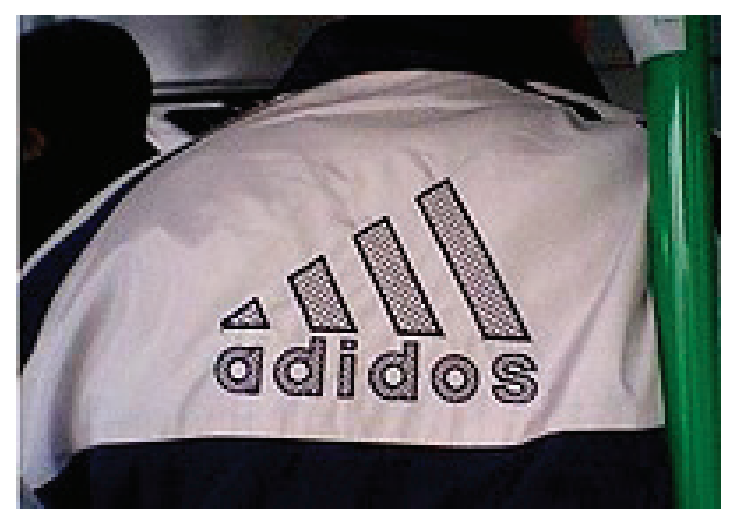

Figura 11 - Uso plagiado da identidade visual Adidas em vestuário.

Fonte: (MELLO, 2011). 


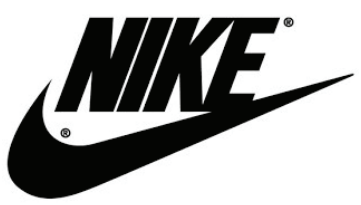

Figura 12 - Identidade visual Nike.

Fonte: (NIKE, 2017).

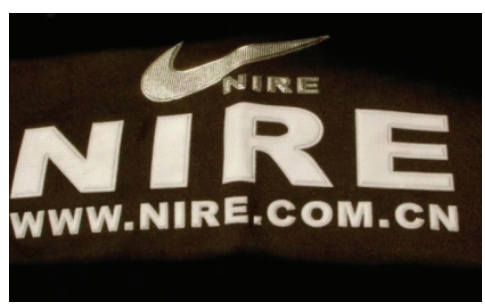

Figura 13 - Uso plagiado da identidade visual Nike em vestuário.

Fonte: (MELLO, 2011).

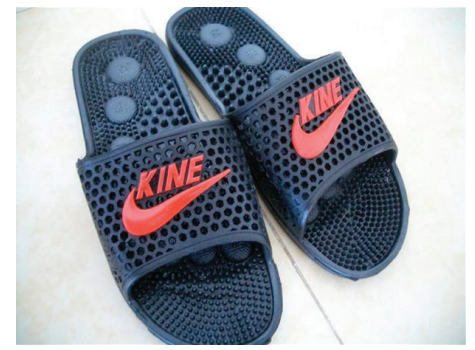

Figura 14 - Uso plagiado da identidade visual Nike em chinelo. Fonte: (MELLO, 2011).

Mesmo tendo aspectos simbólicos, como marca e identidade visual, citados por seus concorrentes na busca de aceitação e legitimidade, essas empresas permanecem como líderes de mercado, sustentadas pela legitimidade outrora conquistada. Reforçam-se, assim, as contribuições da teoria institucional sobre a necessidade de considerar os aspectos técnicos e simbólicos, propondo a percepção, o tratamento e a interiorização de elementos de cunho cultural, político, cognitivo e simbológico, como valores simbólico-normativos.

Deste modo, é possível considerar os ativos intangíveis como elementos que atendem às questões de perenidade e competitividade. Sendo, assim, marcas, inovação, sustentabilidade, governança, capital intelectual e conheci- mento corporativo são exemplos de diferenciais competitivos (ALCADE, 2009). Nesse sentido, Yang e Su (2014) defendem a confluência entre legitimidade e ativos intangíveis, como um importante ponto para o desenvolvimento e a aplicação da teoria institucional no campo do marketing empresarial.

\section{CONSIDERAÇÕES FINAIS}

Este ensaio buscou fomentar uma discussão sobre a importância da marca como ativo intangível no processo de legitimação e diferencial competitivo organizacional, respaldando-se nas orientações e nos pressupostos da teoria institucional. Pôde-se perceber que a competição entre os mercados exige que as organizações gerenciem, de forma eficaz, seus recursos. Contudo, nem todos os recursos podem garantir uma vantagem competitiva sustentável, visto que alguns podem ser imitados, facilmente substituídos ou comercializáveis.

Além disso, a perspectiva institucional abandona a concepção de um ambiente organizacional formado, exclusivamente, por recursos humanos, materiais e econômicos para destacar a presença de elementos culturais como valores, símbolos, mitos, sistema de crenças e programas profissionais. Nesse sentido, a marca configura-se como um importante ativo estratégico, meio sustentável de diferenciação e legitimação para a empresa, capaz de carregar valores simbólicos e agregar um maior valor aos bens disponibilizados no mercado.

Nos casos analisados neste ensaio, a legitimidade que as empresas possuem junto ao mercado advém, claramente, dos aspectos simbólicos de seus ativos intangíveis, algo que vai além de seus processos, aspectos técnicos e estruturas organizacionais. Essa legitimidade pode ser comprovada quando, por exemplo, veem suas ações de marketing imitadas. Se nos baseássemos em teorias ambientais que desprezam a existência de variáveis simbológicas nos ambientes organizacionais, dificilmente encontraríamos justificativas plausíveis para o sucesso e a legitimação dessas organizações imitadas 
em seus mercados de atuação.

Pelo lado das imitadoras, as explicações para a adoção dessas práticas de isomorfismo mimético recaem sob a crença de que, ao menos temporariamente, serão visualizadas no mercado. Entretanto, esses esclarecimentos não dão um bom relato de como a prática se espalha com o tempo, visto que ela é não sustentável em médio e longo prazo, além de ser incapaz de criar diferencial competitivo permanente junto ao cliente. Ao contrário, essas práticas de isomorfismo contribuem para consolidar ainda mais a legitimidade das organizações imitadas.

Vale ressaltar que este estudo optou por analisar o poder das marcas sob a ótica da teoria institucional. Todavia, outras teorias da Administração, assim como outras temáticas que não marcas, poderiam ter sido utilizadas aqui. Similarmente, trabalhos futuros podem avaliar a influência que o conjunto de aspectos técnicos e estruturas organizacionais possui no processo de legitimação organizacional, de modo a verificar, empiricamente, quais as vantagens da combinação desse aos aspectos simbólicos do ambiente institucional. Por fim, destaca-se que, por se tratar de um ensaio teórico, as percepções e as reflexões críticas dos autores representam possíveis limitações a este estudo.

\section{CONSIDERATIONS ON THE SYMBOLIC ASPECTS OF BRANDS FROM THE STANDPOINT OF THE INSTITUTIONAL THEORY}

\section{ABSTRACT}

This theoretical essay sought to stimulate a discussion about the importance of the brand as an intangible resource in the legitimacy process and organizational competitive differential, from the guidelines and assumptions of institutional theory. The institutional perspective leaves behind the conception of an organizational environment formed exclusively by human, material and economic resources to highlight the presence of cultural elements such as values, symbols, myths, belief systems and professional programs. In this sense, the brand is an important strategic resource, sustainable source of differentiation and legitimacy for the organization, carrying symbolic values and adding a greater value to the organizational products.

Keywords: Brand. Institutional Theory. Isomorphism. Intangible Resources.

\section{REFLEXIONES SOBRE LOS ASPECTOS SIMBÓLICOS DE LAS MARCAS BAJO LA ÓPTICA DE LA TEORÍA INSTITUCIONAL}

\section{RESUMEN}

Este ensayo teórico buscó incitar una discusión sobre la importancia de la marca como activo intangible en el proceso de legitimación y diferencial competitivo organizacional, apoyándose en las orientaciones y en los presupuestos de la teoría institucional. La perspectiva institucional abandona la concepción de un ambiente organizacional formado, exclusivamente, por recursos humanos, materiales y económicos para destacar la presencia de elementos culturales como valores, símbolos, mitos, sistemas de creencias y programas profesionales. Así, la marca caracterizase como un importante activo estratégico, medio sustentable de diferenciación y legitimación para la empresa, capaz de cargar valores simbólicos y agregar un mayor valor a los recursos disponibles en el mercado.

Palabras-clave: Marca. Teoría Institucional. Isomorfismo. Activos Intangibles.

1 Plus-size é o termo utilizado para se referir a pessoas que usam roupas no tamanho $12-24$, no padrão da indústria da moda norte-americana

\section{REFERÊNCIAS}

AAKER, D. A. On Branding: 20 princípios que decidem o sucesso das marcas. Porto Alegre: Bookman, 2015. 
ADIDAS. Site oficial. Disponível em: <http:// www.adidas.com.br/>. Acesso em: 17 jun. 2017.

ALCADE, T. Tornar visível o invisível. Revista Consumidor Moderno, São Paulo, p. 6874, ago. 2009

ASSIS, L. B. et al. O isomorfismo entre executivos nas maiores empresas brasileiras. Revista Interinstitucional de Psicologia, Minas Gerais, v. 3, p. 95-107, 2010.

BARREIRINHAS, Ana Claudia. Chocolate em pó. 2015. Disponível em: $<$ http://eufacocozinhasemlactose.blogspot.com.br/2015/11/ chocolate-em-po-vai-uma-dica-valiosa.html>. Acesso: 17 jun. 2017.

BIG MUNDO INFANTIL. [Produto de limpeza multiuso Veja]. 2013. Disponível em: $<$ www.bigmundoinfantil.com/>. Acesso em: 17 jun. 2017.

CAllado, A. A. C.; CALlADO, A. L. C.; ALMEIDA, M. J. Isomorfismo e práticas de gestão de custos: um estudo empírico entre empresas do porto digital a partir da teoria institucional. In: ANPCONT - ASSOCIAÇÃO DOS PROGRAMAS DE PÓS-GRADUAÇÃO EM CIÊNCIAS CONTÁBEIS, 2011, Vitória. Anais... Vitória: ANPCONT, 2011.

CARVALHO, A. P. et al. O papel e as contribuições da teoria institucional para a teoria da inovação. Espacios, Caracas, Venezuela, v. 37, n. $30,2016$.

CARVALHO, C. A.; VIEIRA, M. M. F. Organizações, cultura e desenvolvimento local: a agenda de pesquisa do observatório da realidade organizacional. Recife: UFPE, 2003.

CARVALHO, C. A.; VIEIRA, M. M. F.; LOPES, F. D. Contribuições da perspectiva institucional para análise das organizações. In: ENCONTRO ANUAL DA ANPAD, 23., 1999, Foz do Iguaçu. Anais... Foz do Iguaçu: Anpad, 1999.
CHANDRA, A.; GRIFFITH, D. A.; RYANS JUNIOR, J. K. Advertising standardization in India: US multinational experience. Internacional Journal of Advertising, v. 21, p. 47-66, 2002.

CIMATTI, M. C. B. O poder da marca: uma análise sobre o espaço simbólico das marcas no contexto sócio-cultural contemporâneo. Revista Communicare, v. 7, n. 1, p. 135-144, 2007.

DACIN, M. T.; GOODSTEIN, J.; SCOTT, W. $\mathrm{R}$. Institutional theory and institutional change. Academy of Management Journal, v. 45, n. 1, p. 45-57, 2002.

DICAS PARA O CABELO. Hidratação com amido de milho. 2012. Disponível em: $<$ http:// www.dicasparaocabelo.com.br/2012/10/resenha-hidratacao-com-amido-de-milho-e.html>. Acesso: 17 jun. 2017.

DIMAGGIO, P. J.; POWELL, W. W. A gaiola de ferro revisitada: Isomorfismo institucional e racionalidade coletiva nos campos organizacionais. RAE, v. 45, n. 2, p. 74-89, 2005.

DOLBEC, P. Y.; FISCHER, E. Refashioning a field? Connected consumers and institutional dynamics in markets. Journal of Consumer Research, v. 41, n. 6, p. 1447-1468, 2015.

DUARTE, D. V.; TAVARES, B. Institucionalismo e determinações governamentais. In: ENCONTRO DE ADMINISTRAÇÃO PÚBLICA E GOVERNO, 2012, Salvador, BA. Anais... Salvador, BA: ENAPG/ANPAD, 2012. p. 1-16.

FORBES BRASIL. 50 marcas mais valiosas

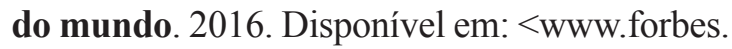
com.br/listas/2016/05/50-marcas-mais-valiosas-do-mundo-em2016>. Acesso em: 22 jun. 2017.

GREENWOOD, R. et al. Institutional complexity and organizational responses. The Academy of Management Annals, v. 5, n. 1, p. 317-371, 2011. 
GUARIDO FILHO, E. R.; MACHADO-DA-SILVA, C. L.; GONÇALVES, S. A. Institucionalização da teoria institucional nos contextos dos estudos organizacionais no Brasil. In: ENCONTRO DA ANPAD, 33., 2009, São Paulo. Anais... São Paulo: Anpad, 2009. p. 1-16.

HOLT, D. B. Why do brands cause trouble? a dialectical theory of consumer culture and branding. Journal of Consumer Research, v. 29, n. 1, p. 70-90, 2002.

KAPFERER, J. N. The New Strategic Brand Management: Advanced Insights and Strategic Thinking. Londres: KoganPage, 2012.

KELLER, K. L. Reflections on customer-based brand equity: perspectives, progress, and priorities. Academy of Marketing Science, v. 6, p. 1-16, 2016.

LOWIS DESING. [Cereal de flocos de milho Sucrilhos]. 2012. Disponível em: $<$ www.lowisdesign.com.br/>. Acesso em: 17 jun. 2017.

MELLO, F. B. Um tênis Like, uma camisa Adidos, um celular Nokla: é o ataque dos clones. 2011. Disponível em: <http://www. administradores.com.br/noticias/marketing/ um-tenis-like-uma-camisa-adidos-um-celular-nokla-e-o-ataque-dos-clones $>$. Acesso em: 17 jun. 2017.

MEYER, J. W.; ROWAN, B. Institutionalized organizations: formal structure as myth and ceremony. In: DIMAGGIO, P. J.; POWELL, W. W. (Orgs.). The new institutionalism in organizational analysis. Chicago: The University of Chicago Press, 1991.

MOTTA, F. C.; VASCONCELOS, I. F. Teoria geral da administração. São Paulo: Thomson Learning, 2002.

NIKE. Site oficial. Disponível em: <http:// www.nike.com.br/>. Acesso em: 17 jun. 2017.
PINHO, J. B. O poder das marcas. 3. ed. São Paulo: Summus Editora, 1996.

PORTUGAL, Mirela. Acusada de plágio, marca terá de retirar geleia do mercado. 2014. Disponível em: <http://exame.abril.com. br/marketing/noticias/acusada-de-plagio-marca-tera-de-retirar-geleia-do-mercado $>$. Acesso em: 17 jun. 2017.

PRATES, A. A. P. Organização e instituição no velho e novo institucionalismo. In: RODRIGUES, S. B.; CUNHA, M. P. Novas perspectivas na administração de empresas. São Paulo: Iglu Editora, 2000.

REICH, R. B. O futuro do sucesso: o equilíbrio entre trabalho e qualidade de vida. São Paulo: Manole, 2002.

RIBEIRO, M. Explorando os limites da extensão de marcas. Revista de Administração Mackenzie, v. 7, n. 3, p. 90-111, 2006.

SABONETE terá que mudar embalagem para não ser confundido com concorrente. 2012. Disponível em: $<$ http://ooutroladodamoeda. com.br/2012/04/sabonete-tera-que-mudar-embalagem-para-nao-ser-confundido-com-concorrente>. Acesso em: 17 jun. 2017.

SCARABOTO, D.; FISCHER, E. Frustrated fatshionistas: An institutional theory perspective on consumer quests for greater choice in mainstream markets. Journal of Consumer Research, v. 39, n. 6, p.1 234-1257, 2013.

SCOTT, W. R. Teoria institucional. Thousand Oaks, CA: Sage, 2004.

STUART, H. Corporate branding and rebranding: an institutional logics perspective. Journal of Product \& Brand Management, v. 27, n. 1, p. $96-100,2018$.

SUDDABY, R. Challenges for institutional 
theory. Journal of Management Inquiry, v. 19, p. 14-20, 2010.

THORNTON, P. H.; OCASIO, W.; LOUNSBURY, M. The institutional logics perspective. Oxford: Oxford University Press, 2012.

VALOR ECONÔMICO. [Coca-Cola]. 2012. Disponível em: < valoreconomico.com $>$. Acesso em: 17 jun. 2017.

WASHINGTON, M.; PATTERSON, K. Hostile takeover or joint venture: Connections between institutional theory and sport management research. Sport Management Review, v. 14, n. 1, p. 1-12, 2011.

YANG, Z.; SU, C. Institutional theory in business marketing: a conceptual framework and future directions. Industrial Marketing Management, v. 43, n. 5, p. 721-725, 2014.

ZORZETTO, Nayara. Plagio ou genérico? 2012. Disponível em: <http://artedepropaganda.blogspot.com.br/2012/06/plagio-ou-generico.html>. Acesso em: 17 jun. 2017. 